\title{
Discussion and Analysis of External Corporate Creditors' Protection of Rights and Interests --- A Stakeholders Perspective
}

\author{
Shi Sun \\ Business School, Sichuan University, Chengdu, Sichuan, China
}

\begin{abstract}
The limited liability system transfers risk from shareholders to the company creditors. Due to that shareholders participate in company internal governance, the shareholders are often in a dominant position in the company's internal information, while in many cases, creditors are in the environment of information asymmetry, which makes it hard for the interests of the creditors to be fully protected. Therefore, how to achieve the real equal rights and interests between shareholders and creditors? This paper argues that there are three measures to solve this issue, including enhancing the participating degree of creditors in the corporate governance, improving the rights and interests protection system of passive creditors and perfecting the mechanism of credit rating.
\end{abstract}

Keywords—-shareholders, outside creditors, measures

\section{企业外部债权人权益保护问题探析 利益相关者视角}

\author{
孙诗 \\ 四川大学商学院, 成都, 四川, 中国
}

\begin{abstract}
摘 要 有限责任制度的出现把原本由股东承担的风险部分的转移给了公司外部的债权人, 但遗憾的是外部债权人并没有因 为有限责任制让自己承担了比无限责任制度更多的风险而获得相对应的法律上的权益保护和支持, 这使得有限责任制度成了造成 股东与债权人财务不公平的始作俑者; 此外, 由于股东能够参与公司内部治理, 所以股东往往能够在公司内部信息的获取上面占 据优势, 这使得在很多情况下股东和债权人处在信息不对称的环境里, 债权人的利益难以得到充分的保护, 股东与债权人之间的 权益不对等。那么如何才能实现股东与债权人之间的权益的对等呢? 本文认为可以从三个方面来采取措施，包括增加主动债权人 参加公司治理的程度、完善被动债权人权益保护制度、完善信用评级机制。
\end{abstract}

关键词 股东 外部债权人 措施

\section{1. 引言}

企业的债权人根据其是否属于企业内部人员分为内 部债权人（主要涉及员工）和外部债权人（可能涉及银 行、投资公司、供应商、消费者等）。“股东和 债权人都是企业的第一层级利益相关者。'研究表明, 一

\footnotetext{
${ }^{1}$ Freeman 和 Clarkson 根据不同利益相关者对公司经营的重要 性, 将利益相关者分为第一层级利益相关者和第二层级利益相 关者。第一层级利益相关者指对公司存续或经营不可或缺的人， 通常包括股东、债权人、政府、社区等; 第二层级利益相关者 主要有媒体和其他特殊利益者。
}

个国家对其债权人的保护程度越强、合同执行效率越高、 其私营信贷规模越大也更高。（张世林，才国伟，2012） 这说明保护债权人的利益对于激活资本信贷活力, 推动 一个国家的经济发展有着重要作用。在我国, 由于法律 疏忽了对债权人利益的保护问题而使得债权人在发放贷 款上颇为谨慎。就拿典型的银行债权人来讲, 其贷款主 要面向业绩稳定的国有企业; 一般的民营企业, 特别是 小微企业很难获得银行的贷款。究其原因, 一方面是我 国法律对债权人权益的保护还不够, 所以银行等债权人 会更倾向于贷款给更有保障的国有企业; 另一方面是债 务人缺乏社会责任感, 利用现有法律监管的漏洞, 侵犯 
债权人等利益相关者的权益。近年来, 资本市场对私营 企业的扶持力度逐渐加大, 但正是在这样的情况下, 债 权人权益保护的问题更加应该及时得到完善; 否则债权 人的积极性就又会受到打击, 这对于整个社会经济的和 谐健康发展是十分不利的。

不管公司利益这一概念如何拓展, 目前为止都无法 改变外部债权人与公司、公司内部人员的薄弱联系, 特 别是外部债权人无法深入公司的日常运作; 另一方面, 这些债权人与公司之间存在庞大的债权债务关系也仅仅 由这薄弱的纽带所维持, 特别是公司有限责任的引入使 得债权人不能追究公司股东的个人财产, 由此带来对债 权人利益保护的不确定性和迫切性。” (陈东, 2010) 我国现行 《公司法》对外部债权人权利的保护相较于以 前（2006 年前）已经有了较大的进步; 但是目前的法律 法规仍然存在一些不足之处, 主要表现在对债权人利益 的保护仍然倾向于单方面对企业股东等的行为进行约束 而并没有赋予债权人足够的事前主动参与权, 这使得债 权人的权益的保护总是存在漏洞并且滞后; 而当债权人 权益受到侵害时，法律方面也没有足够完善的补偿机制。 例如, 《公司法》第二十一条规定: “公司的控股股东、 实际控制人、董事、监事、高级管理人员不得利用其关 联关系损害公司利益。违反前款规定，给公司造成损失 的, 应当承担赔偿责任。” 这里就并未谈及关联交易对 债权人权益造成侵害及公司应对债权人采取的补偿措 施。而我国《破产法》对债权人的保护也是属于事后保 护, 对债权人采用事后补偿制度。种种迹象表明, 我国 公司股东和债权人之间的财务不公平现象仍然存在, 本 文将在现有研究的基础上, 对造成这种财务不公平现象 的根本原因进行剖析, 并提出改善债权人不公平处境的 措施。

\section{2. 债权人弱势地位产生的原因}

股东常常在公司治理中忽略债权人利益的保护问 题, 有意无意的把风险过度转嫁给了外部的债权人, 使 得公司在出现财务危机和破产时, 债权人的利益受到侵 害, 引发股东和债权人之间的财务不公平。学者们对于 这一问题产生的具体原因进行了大量的探讨, 总的来讲, 这种不公平现象的产生主要有以下几个方面的原因:

\section{1 有限责任制度更有利于保护股东而非债权人}

公司组织形式经历了无限责任制度和有限责任制度 两个发展阶段, 并且有限责任制度已经成为现代社会最 为普遍和典型的公司组织形式。有限责任制公司的产生 在一定程度上降低了股东投资的风险，提高了股东的投 资意愿, 促进了资本的聚集, 具有比无限责任制度更为 显著的经济功能, 它是商品经济发展到一定阶段的必然 产物; 但是有限责任制度并没有真正的化解投资风险,
而只是把风险部分的转嫁给了公司外部的债权人。在有 限责任制的前提下, 股东在公司经营中就更加愿意冒风 险, 因为他们只需承担部分风险就可以获得超额的收益; 如果投资失败, 股东只负有限责任, 部分损失将由债权 人承担。由此可见, 有限责任制度分散了股东的投资风 险, 而且会促使股东在公司决策过程中为提高收益而冒 更大的风险, 却增加了债权人的风险。

\section{2 信息的不对称降低了债权人对风险的把控能力}

根据债权债务关系是主动发生还是被动发生, 可以 将债权人分为主动债权人和被动债权人。主动债权人是 指与公司存在契约关系的债权人, 银行、投资公司等金 融机构通常属于这一类债权人。这一类债权人通常比被 动债权人更专业, 规避风险的能力更强。一般来讲, 在 公司与主动债权人达成契约关系之前, 主动债权人会对 公司的财务状况、经营业绩和未来的可持续发展能力做 出评估, 以合理地规避风险; 此外主动债权人可以通过 要求公司股东以个人名义提供担保、限制公司负债比率 和分红行为来控制风险。表面上看, 通过这样的程序可 以使主动债权人的利益得到很大程度的保障; 但是实际 上, 这里面仍然存在着由于信息不对称造成的风险。首 先, 债权人未必能够真实地了解到公司的经营状况, 因 为公司管理层有可能对其财务报表和公司的一些真实情 况加以粉饰; 其次, 在公司拿到借款后, 由于债权人不 能时刻对公司行为进行监督, 所以股东仍然可能通过一 些更为隐蔽的方式对公司资产进行转移, 诸如关联方交 易等。而对于被动债权人而言, 其权益往往较主动债权 人而言更加容易遭遇财务不公平; 因为信息不对称问题 在被动债权人这里表现得更为突出。诸如时下广受关注 的环境污染问题和食品安全问题对社会大众和相关消费 者权益的侵害是有过之而无不及; 在零售领域, 供应商 也是常受压迫的对象; 但对于被动债权人来讲, 他们的 权益并未得到应有的保护。

\section{3. 解决债权人弱势现象可以采取的措施}

或许有限责任制将公司经营的风险进行一定程度的 分散是无法避免的, 但是由此引发的股东与债权人之间 的财务不公平却是不能够忽略的问题。因此, 建立更为 健全的债权人权益保护机制是十分有必要的。因此有学 者提出对有限责任制度予以重新考虑, 呼呼重新追就股 东的个人责任; 当然, 这并不意味着公司要回到无限责 任制度上面来, 而是可以通过建立针对有限责任制度不 足之处的补充制度来解决财务不公平的问题。

\section{1 增加外部主动债权人参与公司治理的程度}

有限责任制将原本由股东承担的风险部分的转移给 
了债权人，但是股东由于在公司治理上拥有比债权人更 大的权力, 所以股东往往在参与公司治理的过程中, 可 以获得信息优势从而能更好的保护自己的利益; 而对于 承担了部分风险但却不具有信息优势的债权人而言就没 有股东这么幸运了。所以，为了实现股东与债权人之间 的财务公平, 就需要实现两者获取信息的公平, 也就要 求增加债权人参与公司治理的程度。有学者提出应将公 司外部债权人的治理权前置, 但在具体的操作上有的人 认为应该在一定条件下让债权人以独立董事的身份参与 公司治理; 有的人认为可以让债权人成为监事会的成员。 然而, 无论是给与债权人独立董事身份, 还是监事会成 员的身份, 都可以让债权人参与到公司的治理中, 解决 股东与债权人信息不对称的问题, 并将债权人权益保护 由事后弥补转为事前的控制, 从而使股东与债权人之间 实现财务公平; 但结合现行的法律制度来讲, 让债权人 成为监事会成员比让其成为独立董事成员更为可行。我 国法律对独立董事要求其与公司没有利益关联, 因债权 人属于公司的利益相关者, 所以不太符合独立董事的要 求; 而给与债权人监事会成员的位置则是可行的, 虽然 目前公司监事会主要是为股东大会服务, 但是如果将其 服务对象扩大至债权人, 那么就可以很好的解决债权人 与股东之间信息不对称的问题。

\section{2 完善外部被动债权人权益保护制度}

现阶段, 我国企业的社会责任感仍然有待加强。对 于主动债权人来讲, 他们具有比被动债权人更强的维权 意识, 而且可以通过契约和法律来捍卫自己的权利。但 在我国, 大多数消费者和社会公众的维权意识是非常淡 薄的, 这使得企业对被动债权人的利益也不够重视, 近 些年来, 食品安全和环境污染的问题频繁发生就说明了 这个问题。所以我国法律在保护被动债权人利益方面还 有待加强。比如加强企业监管, 加大惩罚力度来提高企 业的违规成本。

\section{3 完善信用评级机制}

建立良好的信用评级机制对于增加债券市场信息透 明度, 增加债务人的违约成本，促进资本市场健康可持 续发展有着十分重要的作用。我国的信用评级行业诞生 于上世纪 80 年代末期, 目前我国的信用评级业仍处于初 步发展阶段，在行业监管、法律法规、企业发展等方面 与国际评级机构相比均存在较大差距，而我国规模较大 的 4 家全国性评价机构中，已经有三家都已经被外资收 购，这对于我国金融的发展是十分不利的。因此，我国 应该对国内的信用评级行业的发展予以足够的重视。简 单来讲，应该以下几个方面采取措施：1、完善相关的法 律法规体系，规范外资评级机构持股我国评级机构的行
为, 规范行业内人员的行为。2、提高我国信用评级机构 的公信力, 积极推进我国信用评级企业进入国际市场, 成长为具有国际竞争力的信用评级机构。3、建立健全信 用评级行业的监管体系，促进行业快速健康发展。

\section{参考文献 (References)}

[1] Freeman, 《strategic management-stakeholder approach》, Shanghai Translation Press, 2007.

[2] Weiying Zhang, "Ownership, Governance Structure and Commissioned - Agent Relationship," Journal of Economic Studies, No. 9, 1996, pp.3-15.

[3] Ruilong Yang, Yean Zhou. "Theory of Common Governance Mechanism Under the Logic of Stakeholder Cooperation Enterprise," China Industrial Economy, No. 1, 1998, pp. $38-45$.

[4] Peng Zhou and Hongzhi Zhang, "Negotiations of stakeholders and corporate governance structure," Journal of Economic Studies, No.6 2002, pp.55-62.

[5] Minan Zhang, 《Interests Balance on Company Law》, Beijing: Peking University Press, 2003.

[6] Lin Lu, "The Features of Business Entity Evading Debts and Improvement of bankruptcy legislation," Contemporary Law Review, No1. 2003, pp.67-70.

[7] Honghui Chen, "The requirements of the enterprise stakeholders on their interests", 2004

[8] Zheng Sun, Fengwei Liu, Hui Wang. "Debt, Corporate Governance and Accounting Robustness," China Accounting and Finance Review, No2. 2005, pp.112-116.

[9] Shengdao Gan. "The fairness of the company's financial problems," Journal of Accounting Study, No5. 2012. pp1.

[10] Hongtao Shen and Yifeng Shen, "Identification and Weight Research of Enterprise Stakeholders in China," Journal of Economic Management, No10. 2004, pp. 69-74.

[11] Qianjun Ren. "Improving Credit Rate to Ease the Difficulty of Corporate Finance," China Economic Weekly, No3. 2012.

[12] Mengkui Chen. "Credit Rating for the Analysis of the Influence on the Bond Market,"Journal of Finance, 2012.

[13] Ping He and Meng Jin, "Credit Rating Influence on the Bond Market in China," Journal of Financial Research, No.4, 2010, pp.15-28.

[14] Wei Jiang and Yifeng Shen. "Big Shareholder Control, Asset Replacement and Creditor Protection," Journal of Financial Research, No.12, 2005, pp.95-106.

[15] Xiaohui Li and Zixuan Yang, "Internal Control Quality and Creditor Protection Research," Journal of Audit and Economic Studies, No.2, 2013, pp. 97-105.

[16] Weian Li, Chen Hao. "The Empirical Study of China's Listed 
Company Governance Evaluation on the Board of Supervisors." Journal of Shanghai University of Finance and Economics, No.3, 2006, pp.78-84.
[17] Xu Wang, "Enterprise Life Cycle, Creditors Dynamic Governance and Agency Cost," Journal of Chongqing University, No.5, 2013, pp. 79-85. 